\title{
Influence of Mechanical Milling on the Surface and Morphological Properties of Nanoparticle Molybdenum Disulfide
}

\author{
Wafaa E. Rashwan ${ }^{\mathrm{a}}$, Sahar M. El-Khouly ${ }^{\mathrm{a}}$, Hamdy Farag $^{\mathrm{b}}$ and \\ Abdel-Nasser A. El-Hendawy ${ }^{\mathrm{a}^{*}}$ \\ a Physical Chemistry Department, National Research Center, \\ 1262, ${ }^{b}$ Chemistry Department, Faculty of Science, Mansoura University \\ 35516, Egypt and ${ }^{b}$ Department of Material Process Engineering, \\ Graduate School of Engineering, Kyushu University, Motooka 744, \\ Fukuoka 819-0395, Japan.
}

\begin{abstract}
SYNTHESIS of nested nanoscale $2 \mathrm{H}-\mathrm{MoS}_{2}$ partially ordered layers, through grinding technique, is reported. High surface area of molybdenum disulfide was produced and located in mesoscale, ranging between $14-125 \mathrm{~m}^{2} / \mathrm{g}$. The samples were characterized and investigated by X-ray diffraction, nitrogen adsorption at $-196{ }^{\circ} \mathrm{C}$, scanning electron microscopy (SEM) and transmission electron microscopy (TEM) techniques. The reduction in crystallinity is directly proportional to the grinding time. Grinding was demonstrated to be an effective physical technique for monitoring the crystallite sizes. It mostly affects the number of the stacked $\mathrm{MoS}_{2}$ layers but not the slab lengths. The nitrogen adsorption-desorption isotherms measured were interpreted and analyzed by application of BET equation as well as both $\alpha_{\mathrm{s}}$ and t- methods for surface area calculations. It was discovered that the increase in grinding time led to a decrease in the crystallite sizes, simultaneously, accompanied by a sharp increase in the surface area of the investigated solids.
\end{abstract}

Keywords: TEM, SEM, XRD; $\mathrm{S}_{\mathrm{BET}}, \mathrm{MoS}_{2}$, nanostructure and milling

Transition metal disulfides represent an important class of materials that exhibit numerous and wide applications in many fields such as catalysis, electronics, sensors, photovoltaics, and energy ${ }^{(1-8)}$. This is due to their interesting properties associated with their structure. Molybdenum disulfides are among these dichalcognides that exhibit a number of important applications especially in the sector of catalysis. Hydrotreating of petroleum oil fractions is one that reckon thoroughly on such materials. To meet the recent stringent regulations for benign

* Tel.: +20 50223 2515; fax: +20 23270931 .

E-mail address: elhendawy@yahoo.com. 
environment and to reduce the sulfur level in petroleum middle distillates to less than $10 \mathrm{ppm}$, catalyst research and development is urgently needed. Intensive efforts of investigation have been already achieved in developing such catalysts for hydrotreating reactions ${ }^{(9,10)}$. Molybdenum disulfide is prepared usually by sulfiding molybdenum oxides with $\mathrm{H}_{2} \mathrm{~S} / \mathrm{H}_{2}$ gas mixture. Thermal treatments were demonstrated to control, however partially, the crystallite size of $\mathrm{MoS}_{2}$ in the course of synthesis. Distinguished catalytic activities of bulk $\mathrm{MoS}_{2}$ catalysts has been recently reported ${ }^{(11-12)}$. Crystallite size and layer morphology were ascertained to be a decisive key for activity and selectivity in hydrodesulfurization reactions. Nevertheless, simple techniques to maintain the laminated structure of such metal sulfides are encouraged. Molybdenum disulfides are well known to be found in three different polymorph structures, $2 \mathrm{H}-\mathrm{MoS}_{2}$ (trigonal closed pack with two S-Mo-S units per unit cell), IT-MoS (octahedral with one Mo atom per unit cell) and $3 \mathrm{R}-\mathrm{MoS}_{2}$ (trigonal close packed of three S-Mo-S layers of unit cell). The first one is most stable and abundant structure1. All structures are composed of $\mathrm{MoS}_{2}$ layers in which the spacing between them is typically $6.15 \AA^{(13)}$. Synthesis of $\mathrm{MoS}_{2}$ is a quite delicate process in which a little change in the synthesis routes may lead to a serious change in surface area, crystallite sizes, number of laminated layers, slab lengths, and layer bindings ${ }^{(11,14-16)}$. Thus, distinct impacts on the catalytic properties especially in hydrotreatment reactions are prospective. Kouzo et al., reported a distinct activity in dibenzothiophene hydrodesulfurization of mechanically milled $\mathrm{MoS}_{2}{ }^{(17)}$. However, limited studies have been done on this technique although it is old traditions ${ }^{(16-18)}$.

The aim of the present study is to monitor through milling the sizes of the synthesized $\mathrm{MoS}_{2}$ and investigate the structure and texture of the produced species. Specific details regarding the morphology and surface properties were characterized by XRD, BET, SEM and TEM methods are presented. 
Materials

\section{Experimental}

Ammonium heptamolybdate of high purity grade, $99.9 \%$, was supplied by TCI Company. Other chemicals are available commercially.

Synthesis of $\mathrm{MoS}_{2}$ initial precursor: The preparation procedure for the plane $\mathrm{MoS}_{2}$ was performed according to the procedure described in reference ${ }^{(7,19)}$, however, with some modifications. Briefly, ammonium heptamolybdate tetrahydrate was heat annealed at $850{ }^{\circ} \mathrm{C}$ in a sulfidation medium of $10 \mathrm{wt} \%$ $\mathrm{H}_{2} \mathrm{~S} / \mathrm{H}_{2}$ gas mixture. A quartz microreactor was used for this purpose. The outlet sulfidation gases and reaction products were scrubbed into a trap filled with a saturated solution of $\mathrm{NaOH}$. The sulfidation gas mixture was set to flow from the beginning of the reaction run with a fixed applied flow rate of $30 \mathrm{SCCM}$ and raising temperature rate of $3^{\circ} \mathrm{C} /$ minutes. The sample was subjected to sulfidation at this condition for ca. 80 hours while continue flowing of $\mathrm{H}_{2} \mathrm{~S} / \mathrm{H}_{2}$ gas mixture. Ar gas flush with a rate of 120 SCCM for 30 minutes was applied before cooling down to ambient temperature. The obtained sample was kept in a desiccator for extending processes. This plane $\mathrm{MoS}_{2}$ sample was named as PMS-U.

\section{Milling procedure}

Grinding of PMS-U was fulfilled using the Media Agitating Mill. Ar purging was performed after sample installation. Zerconia balls of an average $3 \mathrm{~mm}$ diameter was used as a media. The mill rotation speed was set at $3000 \mathrm{rpm}$. The sample was subjected to grinding at these conditions under different time intervals which will be shown in the code name. For example, PMS-G-1 refers to the sample subjected to grinding under the previous conditions for 1 hour. Milled samples were kept in a desiccator for analyses.

\section{Samples characterization}

BET surface area: Measurements of the surface area through the measurements of nitrogen adsorption isotherms at $-196^{\circ} \mathrm{C}$ were performed on the automatic micromeritics ASAP 2010C instrument in which volumetric adsorption was utilized. Before measurements, all samples were degassed at $200^{\circ} \mathrm{C}$ for ca. $24 \mathrm{hr}$.

$X$-ray Diffraction (XRD): Rigaku Diffractometer using $\mathrm{Cu} \mathrm{K} \alpha$ radiation $(\lambda=1.54056 \AA)$ was used for X-ray powder diffraction measurements. The sample was subjected to mild mortar grinding before loaded on the cavity of glass disk for analysis. A scan step of $0.02 \theta$ was utilized.

Scanning electron microscope (SEM): SEM micrographs were obtained using Hitachi s-4700 field emission SEM probe. The sample was placed on a strip of copper tape attached to the SEM stub. The operating accelerating voltage was 30 KV.

Transmission electron microscopy (TEM): Transmission electron microscopy (TEM)was used to image the nanoparticles. Imaging were obtained in a Hitachi $9000 \mathrm{UHR}$ working at an accelerating voltage of $200 \mathrm{KV}$. 


\section{Results and Discussion}

Sample Characterization

Figure 1 compares the X-ray diffraction patterns of the plane $\mathrm{MoS}_{2}$ and its comminuted counterparts at different intervals of milling. All patterns correspond to $2 \mathrm{H}-\mathrm{MoS}_{2}$ structure in the powder diffraction file JCPDS card No. 37-1492 which reflects the hexagonal structure of $\mathrm{MoS}_{2}{ }^{(20)}$. The patterns show well-defined extremely sharp peaks of Miller indices at (002). However, a fine shifts in $2 \theta$ for (002) index from 14.14 to 14.35 which corresponds to the spacing of the basal planes of $6.15 \AA$ and $6.25 \AA$, respectively, was observed. This indicates that the interlayer distance of the MoS2 lamellar layers may slightly be expanded. This could be a sign for the curvature nature of the $\mathrm{MoS}_{2}$ layers. The peak width at $2 \theta 14.35^{\circ}$ was highly dependent on the grinding time. This indicates the crystal growth in the c direction, i.e., the high stacking degree of the obtained $\mathrm{MoS}_{2}$ structure. Average crystallite size was estimated from the (002) peak width based on the Scherrer's equation ${ }^{(21)}$ :

$$
C_{002}=K \lambda / \beta \cos \theta
$$

In which $\mathrm{C}$ is the average crystallite size alongside the Miller indices of $\{002\}, \lambda$ is the wavelength of the X-rays used $(1.540 \AA), \mathrm{K}$ is the Scherrer's constant and has a value of $\sim 0.9, \theta$ is the Bragg angle and $\beta$ is the peak width at half height in radians. The crystal growth in the other $h k l$ directions, i.e., (100) associated with the slab length of the $\mathrm{MoS}_{2}$ layers, which are relatively low compared with (002) pattern peaks. Average crystallite size of $\sim 22 \mathrm{~nm}$ was estimated for the hydrothermal synthesized $\mathrm{MoS}_{2}$ before grinding. Results of the estimated crystallite sizes of the present samples were listed in Table 1.

TABLE 1. Crystallite sizes of the ground $\mathrm{MoS}_{2}$ samples extracted from XRD results.

\begin{tabular}{|c|c|}
\hline Sample & Average crystallite size, $\mathbf{n m}$ \\
\hline PMS-U & 22 \\
\hline PMS-G-1 & 15 \\
\hline PMS-G-5 & 10 \\
\hline PMS-G-10 & 7 \\
\hline PMS-G-50 & 3 \\
\hline
\end{tabular}




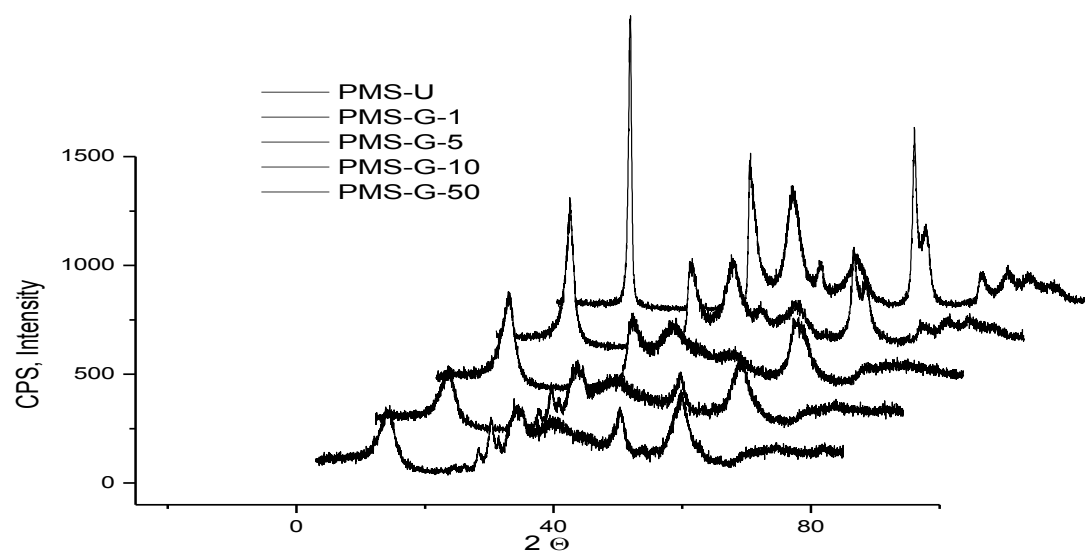

Fig. 1. X-ray diffraction patterns of plane $\mathrm{MoS}_{2}$ and its ground samples at different interval times.

It is interesting to note that with increasing the grinding time the crystallite size in the c-direction gradually decreased up to $\sim 3 \mathrm{~nm}$. In other means, the stacked $\mathrm{MoS}_{2}$ lamellar layers were reduced. On the other hand, the slab lengths of $\mathrm{MoS}_{2}$ were not as much changed as such in the stacks.

Figure 2 ( $a \& b)$ shows the scanning electron micrographs of the hydrothermally synthesized $\mathrm{MoS}_{2}$, sample PMS-U. One may note that the $\mathrm{MoS}_{2}$ particles are agglomerates of disordered balls and somewhat chain like structures. The PMS$\mathrm{U}$ sample is of an average size of ca. $250 \mathrm{~nm}$. Close identity and matching of the agglomerate sizes can be seen from the Figure. This reveals on the reaction homogeneity during the transformation to the $\mathrm{MoS}_{2}$ nanostructure. Figure 3 (a $\& b)$ shows the SEM images of the PMS-G-50 sample. Almost typical view can be observed as for the plane $\mathrm{MoS}_{2}$ sample, Figure 2. Nevertheless, one may observe the high condense of the particles in comparison to plane $\mathrm{MoS}_{2}$. Condensed agglomerates of $\mathrm{MoS}_{2}$ particles may argue to be due to grinding. It is interesting to note from SEM images also the agglomerations of the disordered ball like structure particles. Figure 4 shows the image of TEM of the obtained $\mathrm{MoS}_{2}$ structure. Circular curved layer structure can be seen. Multilayer $\mathrm{MoS}_{2}$ is obvious. It is also interesting to note from SEM images the agglomerations of the disordered ball like structure particles. XRD results demonstrate that as the grinding time increases the crystallite sizes in the c-direction decreases. This means that the number of the stacked $\mathrm{MoS}_{2}$ layers is dramatically reduced. However, the slab lengths, assigned by the XRD patterns at (100) indices were not much affected. The result clearly establishes the feasibility of mechanical route to adjust the particle size of $\mathrm{MoS}_{2}$. Thus, the small BET surface area of ca. 
$14 \mathrm{~m}^{2} / \mathrm{g}$ may be due to the ornamental borders between the agglomerate fringes. Milling was lead to increase dramatically the BET surface area.

Adsorption isotherms of the plane $\mathrm{MoS}_{2}$ sample and the ground $\mathrm{MoS}_{2}$ after 50 $\mathrm{h}$ grinding were depicted in Figure $5(\mathrm{a}, \mathrm{b})$. The analysis of the $\mathrm{N}_{2}$-adsorption isotherm provides quite reasonable assessment of the pore size distributions. One may note that, in all isotherms, the nitrogen uptake was significant only in the low pressure region where $\mathrm{P} / \mathrm{P} 0<0.1$ and then steady increase in the adsorption in the region of $\mathrm{P} / \mathrm{P}^{0}>0.2$. The isotherms can be classified to belong to Type IV from the well known Brunauer, Deming, Deming and Teller (BDDT) IUPAC classification ${ }^{(22)}$. The isotherm indicates the existence of mesoporosity. Furthermore, BET surface areas were determined to be 14 and $125 \mathrm{~m}^{2} / \mathrm{g}$ for the plane $\mathrm{MoS}_{2}$ (PMS-U sample) and PMS-G-50 sample, respectively. The surface area of the PMS-G-50 is about 10 times greater with the use of milling technique, suggesting the formation of very small nested crystallites. This distinguished increase in the BET surface area is further supported by the estimated low crystallinity ( $>4 \mathrm{~nm}$ ) from the XRD results, (Fig. 1).

\section{Surface area and textural parameters determination}

Now, it becomes a typical procedure to apply three most important methods to determine the surface area and some associated data as stated in table 2 . They are evaluated by applying BET equation as well as both $\alpha$ and t- methods.

i) The Brunauer-Emmett-Teller (BET) method to obtain the surface area from physisorption isotherm data through the nitrogen adsorption isotherms at -196 ${ }^{\circ} \mathrm{C}$. For that reason, it is suitable to apply the BET equation ${ }^{(23)}$ through the computerized micromeritcs ASAP 2010 instrument, where volumetric adsorption was used. Before taking the measurements, the sample was out gas at a degree of $200^{\circ} \mathrm{C}$ for $24 \mathrm{hr}$.

$$
\frac{P}{V\left(P^{o}-P\right)}=\frac{1}{V_{m C}}+\frac{(C-1)}{V_{m} C} \cdot \frac{P}{P^{o}}
$$

where $\mathrm{V}$ is the amount of gas adsorbed at the relative pressure $\mathrm{P} / \mathrm{P}^{0}, \mathrm{Vm}$ is the monolayer capacity and $\mathrm{C}$ is a constant which is based on the isotherm shape.

Two representative nitrogen adsorption isotherms of the prepared molybdenum sulfide is shown in Figure 5. Evidently, the isotherm of this solid sample is of IV type. The upward increase in the isotherm at high relative pressure $\geq 0.5$ may be ascribed to the existence of a significant fraction of the surface in mesoscale. This can explain the sharp upward deviation as shown in the Figure $6(\mathrm{a}-\mathrm{d})$ of both plots of $\alpha-$ and $\mathrm{t}-{ }^{(24-28)}$. Some important estimated parameters are summarized in table 2. The entire pore volume $\mathrm{V}_{\mathrm{p}}(\mathrm{ml} / \mathrm{g})$, reported in table 2, was obtained from the volume of liquid nitrogen adsorbed at $\mathrm{P} / \mathrm{P}^{\mathrm{o}}$ too close to saturation i.e. at $\sim 0.95$. The mean pore radius $\mathrm{r}^{-}$for the samples investigated was obtained by applying the relationship:

Egypt. J. Chem. 59, No. 6 (2016) 


$$
\mathrm{r}^{-}(\mathrm{nm})=2 \mathrm{~V}_{\mathrm{p}}(\mathrm{ml} / \mathrm{g}) \cdot 10^{3} / \mathrm{S}^{\mathrm{BET}}\left(\mathrm{m}^{2} / \mathrm{g}\right)
$$

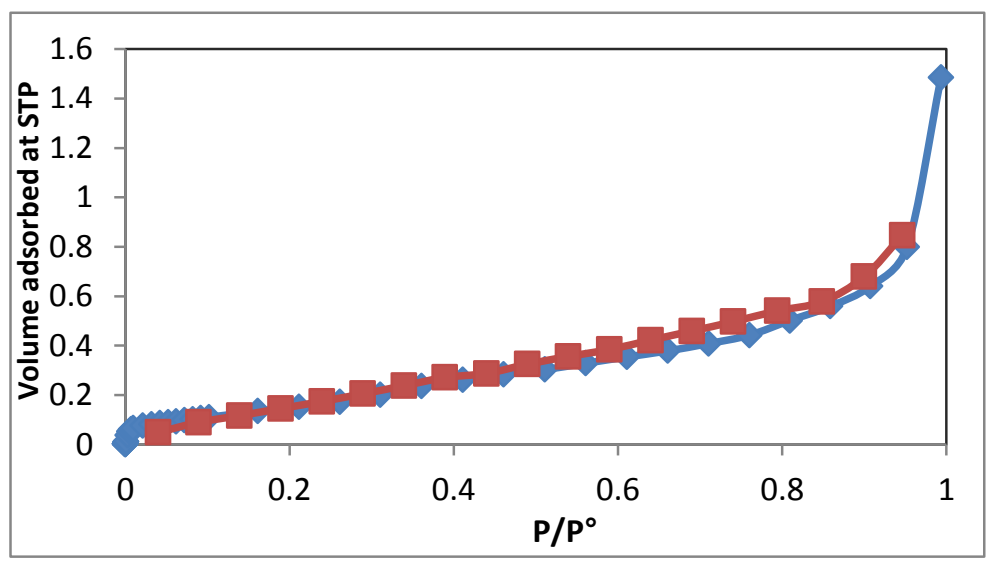

(a)

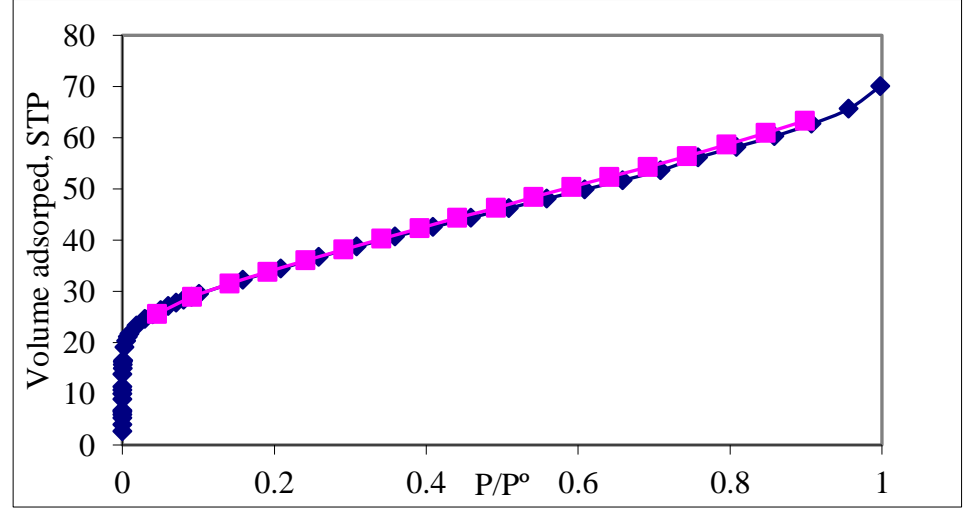

(b)

Fig. 2. N2 adsorption desorption isotherms of the sample investigated (a) PMS-U and (b) PMS-G-50, respectively

The values of $\mathrm{S}_{\mathrm{BET}}, \mathrm{V}_{\mathrm{p}}$ and $\mathrm{r}^{-}$are given inTable 2 .

ii) Two additional independent methods are also used to analyze the nitrogen adsorption isotherm. The t-plot of de-Boer ${ }^{(24,25)}$ and its extension, as $\alpha_{\mathrm{s}}$ by Selles-Perez and Martin-Martin-Martinez ${ }^{(25-30)}$, both plots are shown in Figure $6(\mathrm{a}-\mathrm{d})$. Through the first method, the volumes of gas adsorbed are plotted against the multilayer thickness $\mathrm{t}$ in $\AA$ as measured on a non-porous solid of comparable $\mathrm{C}_{\mathrm{BET}}$ constant ${ }^{(28-30)}$. The second method, on the other hand, plots the volumes of gas adsorbed against the reduced isotherm $\alpha_{\mathrm{s}}$ determined on a standard non-porous solid. Both methods permitted the determination of surface area $\left(S^{t}, S^{\alpha}\right)$, the surface areas were calculated by applying the $t$ - and $\alpha$-methods that are approximately similar to each other (cf. Table 2). The estimated surface 
area by t-plot $\left(\mathrm{S}^{\mathrm{t}}\right)$ was found to be between 19 to $131 \mathrm{~m}^{2} / \mathrm{g}$ while $\mathrm{S}^{\alpha}$ reported ranging $17-128 \mathrm{~m}^{2} / \mathrm{g}$ indicating an intermediate value between $\mathrm{S}^{\mathrm{BET}}$ and $\mathrm{S}^{\mathrm{t}}$. Thus, one can conclude that the alpha method is a high resolution and a more reliable method in determination surface area in such cases. Moreover, the values of mean pore radius $r^{-}(\mathrm{nm})$ are between 4.011- 2.774 reveals that the significant part of these areas are located in mesoscale inside and/or between the grains and layers of the bulk molybdenum sulfide.

It is apparent that the increase of the interval times of mechanical milling of $\mathrm{MoS}_{2}$ produces a significant decrease of the average crystalline size, nm, leading to this sharp increase in the surface areas calculated as can be seen in Fig. 7 and 8 .

TABLE 2. Some textural parameters as evaluated from adsorption isotherms of Nitrogen at $77 \mathrm{~K}$.

\begin{tabular}{|c|c|c|c|c|c|c|c|}
\hline \multirow{2}{*}{$\begin{array}{c}\text { Sample } \\
\text { Notation }\end{array}$} & \multirow{2}{*}{$\begin{array}{c}S_{B E T} \\
\left(m^{2} / g\right)\end{array}$} & \multirow{2}{*}{$\begin{array}{c}V_{P} \\
(m / g)\end{array}$} & \multirow{2}{*}{$\begin{array}{c}r^{-} \\
(n m)\end{array}$} & \multicolumn{2}{|c|}{$\begin{array}{c}\alpha s \\
\text { parameters }\end{array}$} & \multicolumn{2}{|c|}{$\begin{array}{c}\text { t-plot } \\
\text { parameters }\end{array}$} \\
\hline & & & & $\begin{array}{c}\mathbf{S}^{\alpha} \\
\left(\mathbf{m}^{2} / \mathbf{g}\right)\end{array}$ & $\begin{array}{c}S^{\alpha} \\
\left(\mathbf{m}^{2} / g\right)\end{array}$ & $\begin{array}{c}\mathbf{S}^{\mathbf{t}} \\
\left(\mathbf{m}^{2} / \mathbf{g}\right)\end{array}$ & $\begin{array}{c}\mathbf{S}_{n}^{t} \\
\left(\mathbf{m}^{2} / \mathbf{g}\right)\end{array}$ \\
\hline $\begin{array}{c}\text { PMS- } \\
\text { U }\end{array}$ & 14 & 0.028 & 4.011 & 17 & 12 & 19 & 13 \\
\hline $\begin{array}{l}\text { PMS- } \\
\text { G-1 }\end{array}$ & 21 & 0.032 & 3.0476 & 24 & 14 & 27 & 15 \\
\hline $\begin{array}{l}\text { PMS- } \\
\text { G-5 }\end{array}$ & 62 & 0.086 & 2.774 & 63 & 19 & 69 & 21 \\
\hline $\begin{array}{c}\text { PMS- } \\
\text { G-10 }\end{array}$ & 88 & 0.130 & 2.954 & 91 & 23 & 94 & 27 \\
\hline $\begin{array}{c}\text { PMS- } \\
\text { G-50 }\end{array}$ & 125 & 0.206 & 3.296 & 128 & 29 & 131 & 33 \\
\hline
\end{tabular}



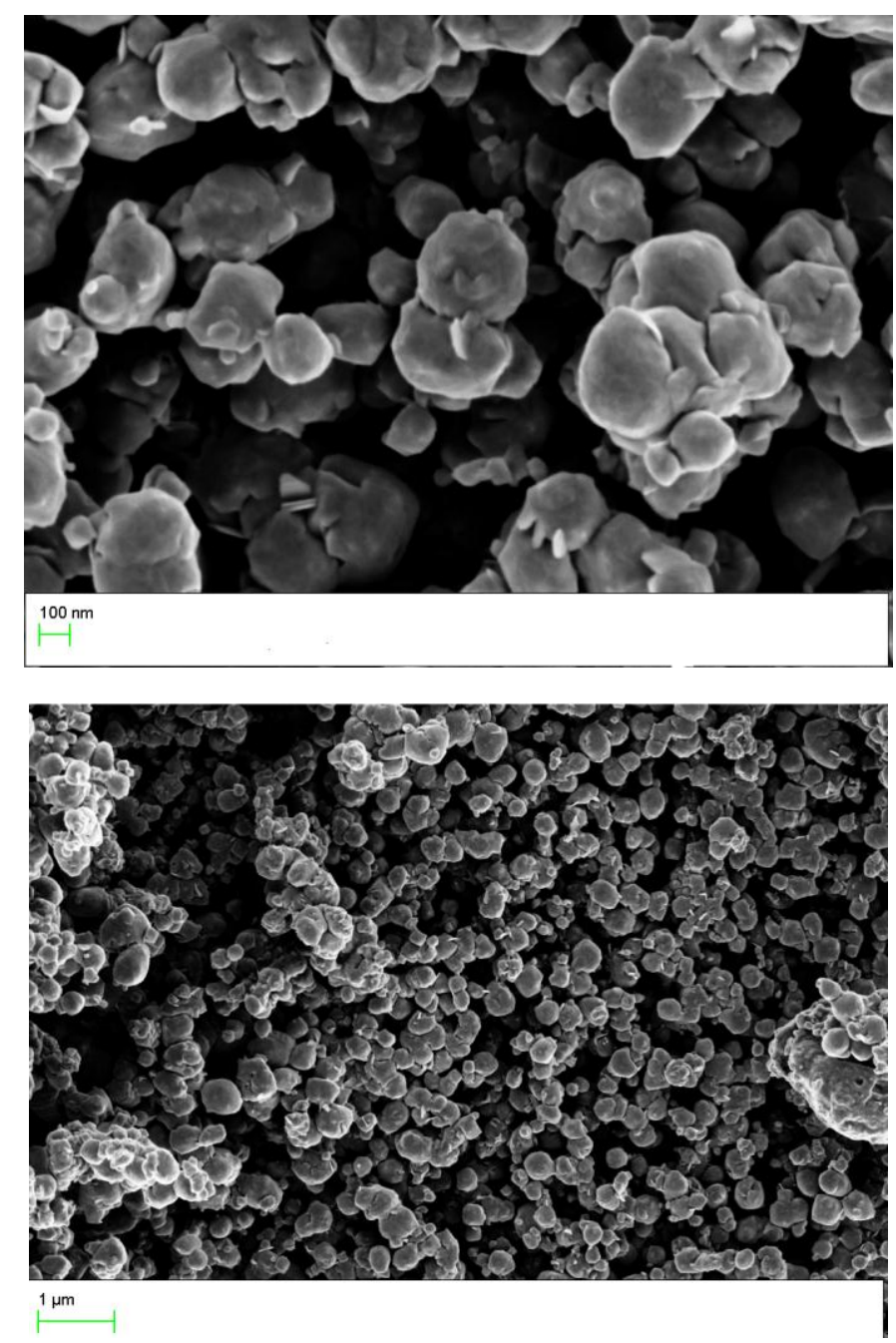

Fig. 3. SEM images of the PMS-U sample at different magnifications. 

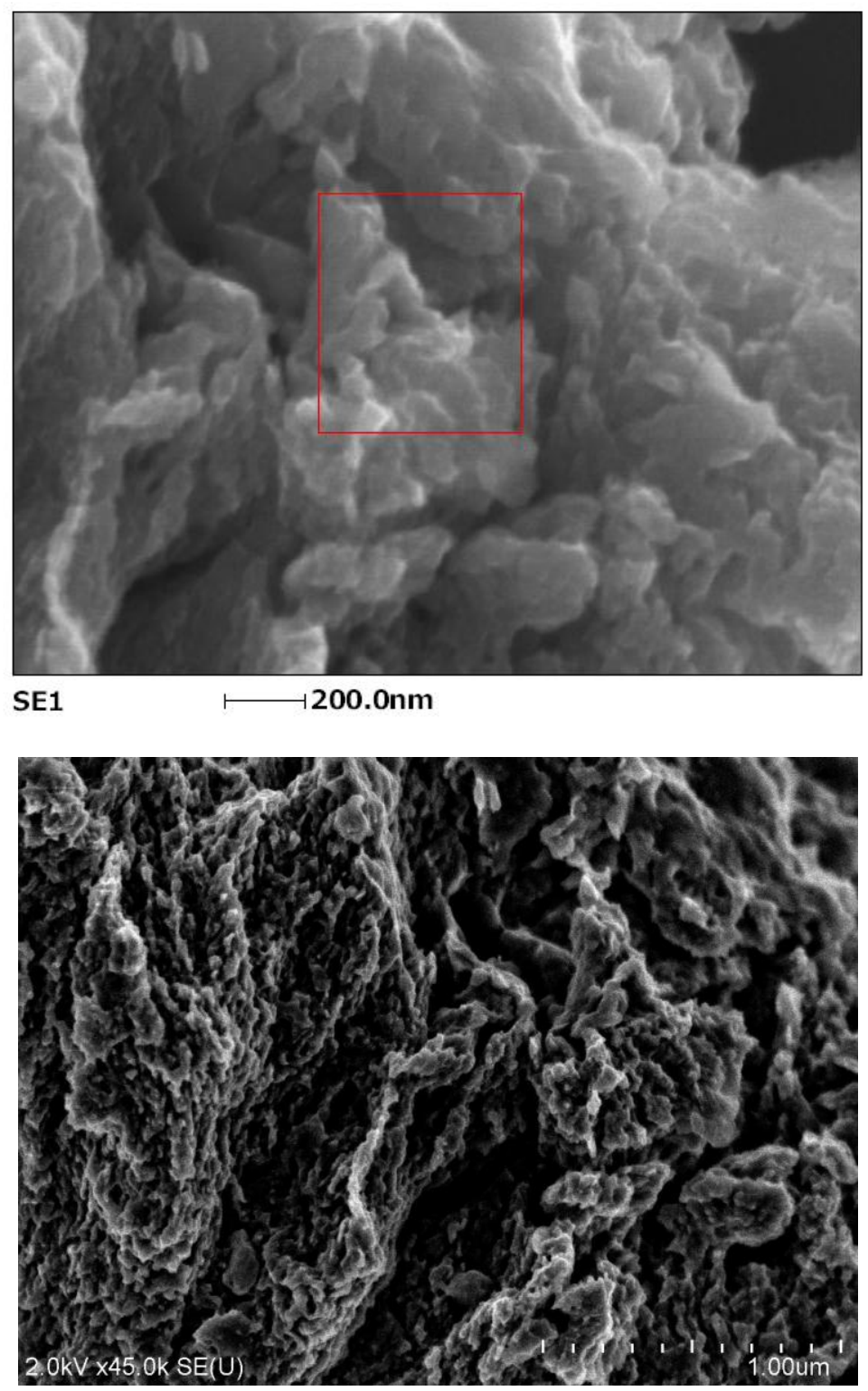

Fig. 4. SEM images of the PMS-G-50 sample at different magnifications. 


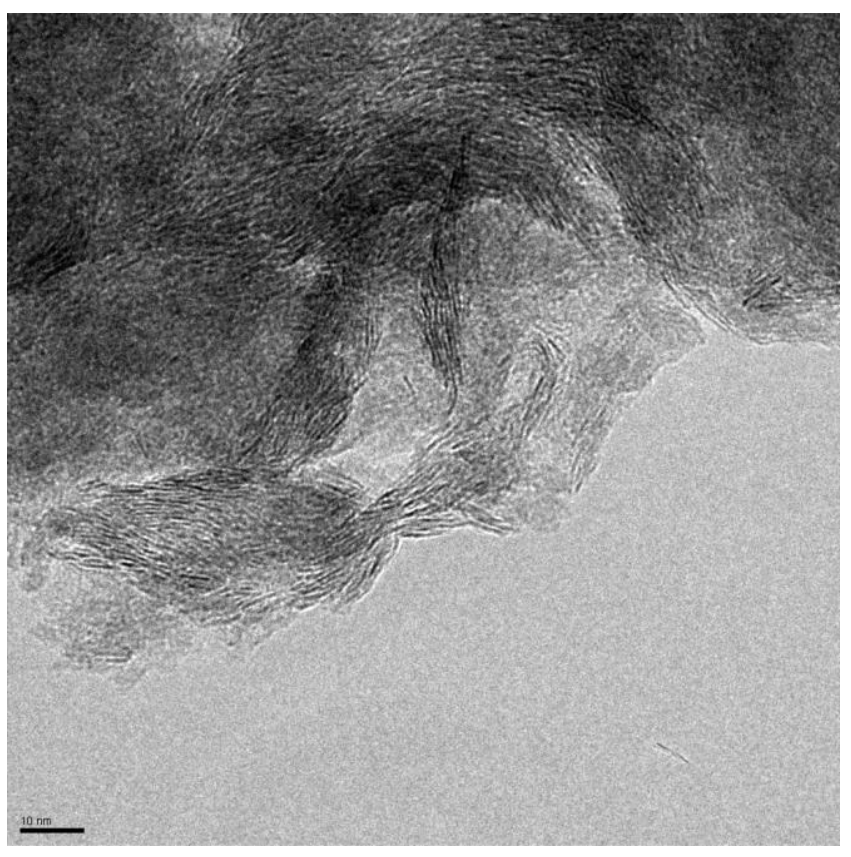

Fig. 5. TEM images of PMS-G-50 sample.
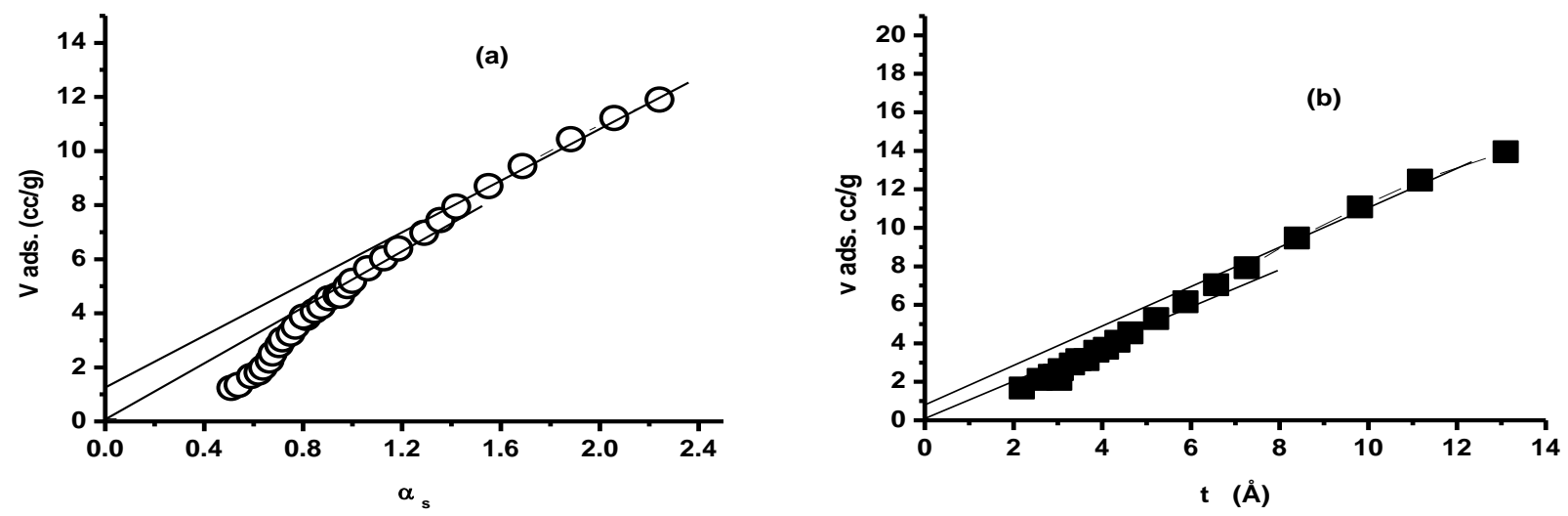

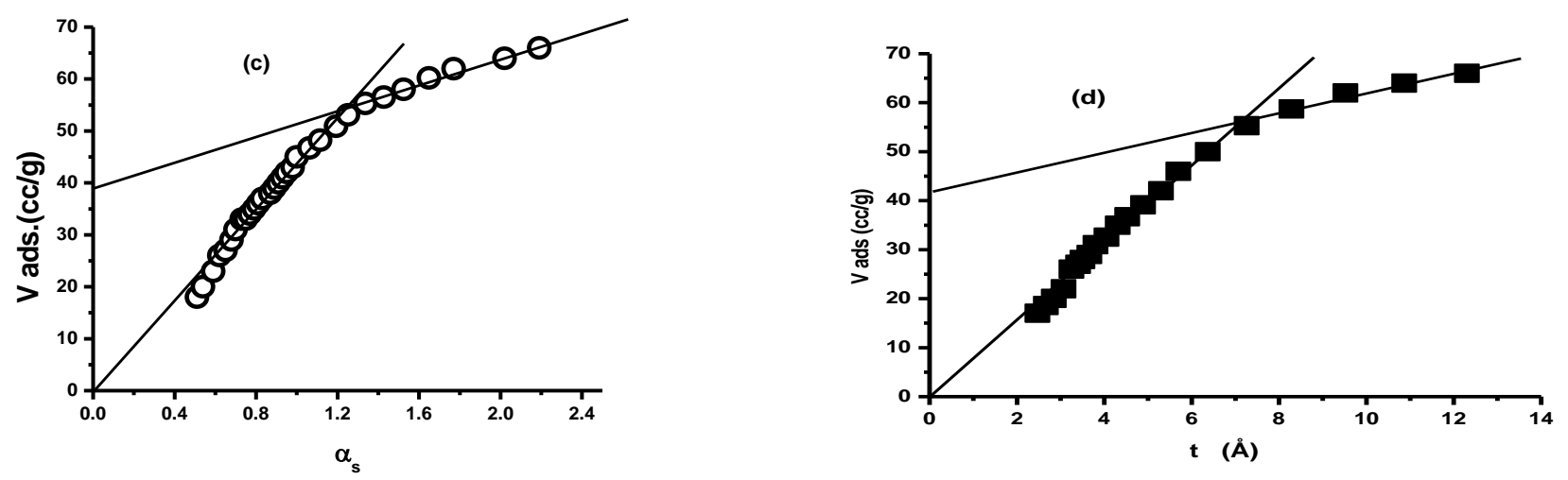

Fig.6. $\alpha_{\mathrm{s}}$ - and t- plots for $\mathrm{N}_{2}$-adsorption isotherm of the samples investigated PMS-U (a,b)and PMS-G-50 as (c,d), respectively.

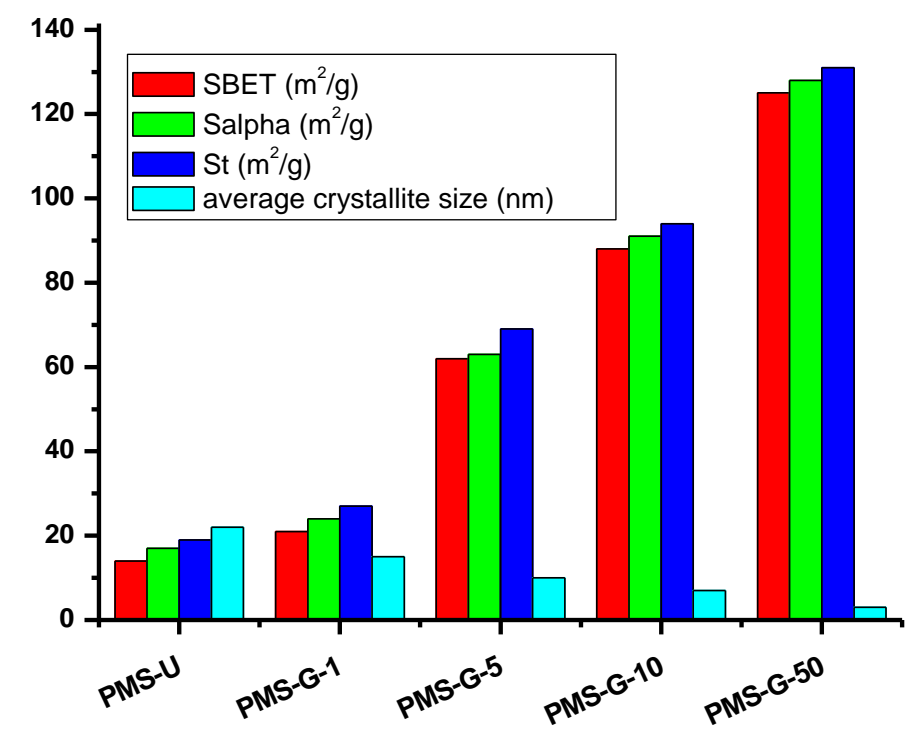

Fig.7. Correlation between the calculated values of surface areas $\left(S^{\mathrm{BET}}, S^{\alpha}, S^{\mathrm{t}} \mathrm{m}^{2} / \mathrm{g}\right)$ and the average of crystallite size of the samples investigated. 
Upon considering the textural parameters in Table 2, it appears evidently that the investigated $\mathrm{MoS}_{2}$ samples are essentially located in the meso-scale, mean pore radii $\mathrm{r} 2.7$ - $4 \mathrm{~nm}$ with low total pore volumes $0.028-0.206 \mathrm{ml} / \mathrm{g}$. Similar to the previous observation, the specific surface areas evaluated from the $\alpha_{\mathrm{s}}$ - plots are higher than the BET apparent surface area to a little extent (-3-21\% higher ). Meanwhile, the t-plots evaluated also much higher values, by about $32 \%$ than the BET - ones. Thus, although we are here dealing in mesoscale solids, yet both the BET and t- surface areas should be taken with caution. Moreover, the increase of the interval grinding time produces an enhancement of meso-phase leading to the appearance of capillary condensation as indicated in the upward deviation in both plots of $\alpha$-s and $t$ - figure 6 . This is also confirmed from relatively higher values of the external surface areas calculated by both plots $\alpha_{s}$ and $t-\left(S^{\alpha}{ }_{n}\right.$ and $\left.S_{n}^{t}\right)$ (Table 2).

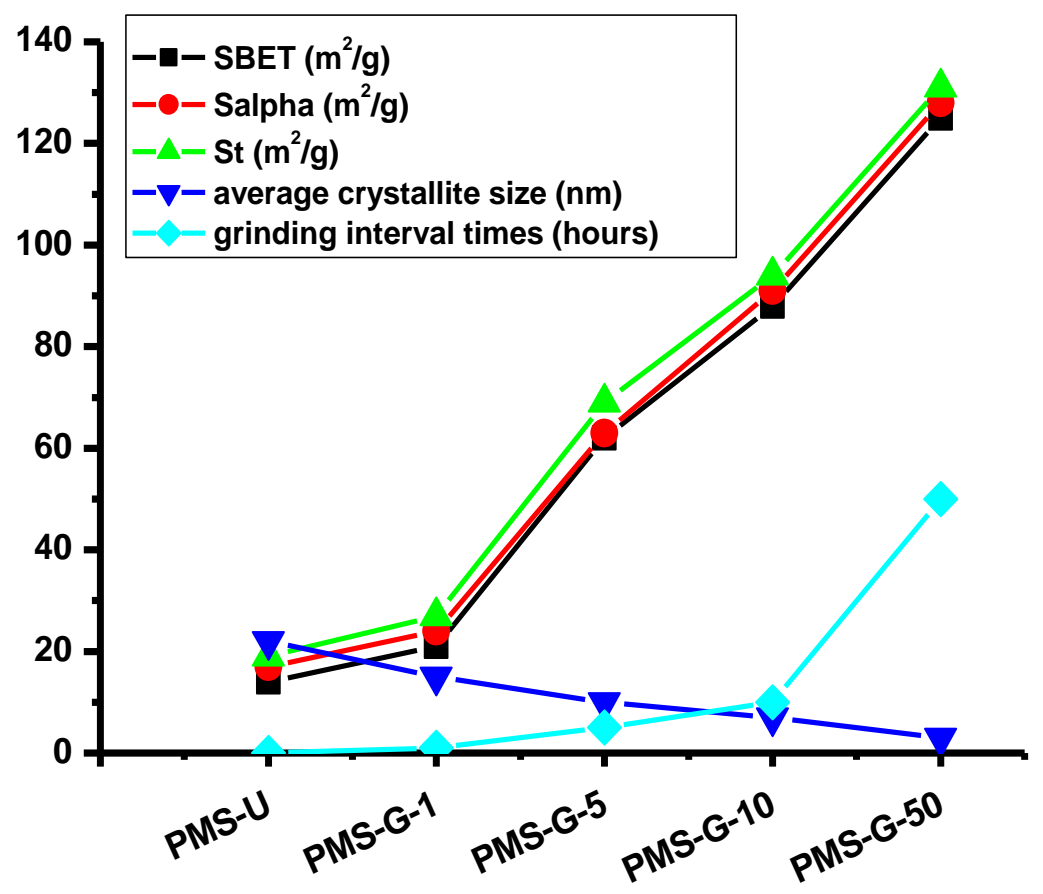

Fig. 8. Variation in the calculated values of surface area $\left(S^{\mathrm{BET}}, S^{\alpha}, S^{t} \mathrm{~m}^{2} / \mathrm{g}\right)$ with the average of crystallite size as function of grinding interval times of the samples investigated (in hours). 


\section{Conclusions}

Attempt was made to monitor the size of nanoscale molybdenum sulfide by milling technique. The method has the advantages to be a simple process for the production of nanosized laminated $\mathrm{MoS}_{2}$ structure. The results reveal that the sample is composed of particle agglomerates of almost typical sizes of ca. 250 $\mathrm{nm}$. Milling of the highly crystalline PMS-U sample for extended time of $50 \mathrm{~h}$ lead to a more condense of these particles. It was further found that the diminishing in crystallinity is due to the decrease in number of the stacked $\mathrm{MoS}_{2}$ layers. The morphology of the samples reveals the predominant of curved multilayer of $\mathrm{MoS}_{2}$.

Treatment of $\mathrm{MoS}_{2}$ with mechanical milling is very effective in producing new phases of $\mathrm{MoS}_{2}$ with reasonable specific surface area up to $\mathrm{S}^{\alpha} 128$ $\mathrm{m}^{2} / \mathrm{g}$, external surface area $\mathrm{S}^{\alpha} \mathrm{n}$ up to $29 \mathrm{~m}^{2} / \mathrm{g}$ and with significant decrease in their average crystallite sizes up to $3 \mathrm{~nm}$. In other words, the increase of interval grinding times of $\mathrm{MoS}_{2}$ led to a sharp decrease in its stacked lamellar layer.

The final general form of the prepared investigated $\mathrm{MoS}_{2}$ samples as well as both the nature of their surface properties and the number of layers; and thus their crystal morphology have significant effects in the catalytic properties for such materials. This indicates that they will have promising applications in many industries in the future, especially in the petroleum refining industry.

\section{References}

1. Novoselov, K.S., Geim, A.K., Morozov, S.V., Jiang, D., Zhang, Y., S. V., Dubonos, S.V., Grigorieva, I.V. and Firsov, A.A., Science, 306, 666-669 (2004).

2. Li, H., Yin, Z., He, Q., Li, H., Huang, X., Lu, G., Fam, D., Tok, A., Q. Zhang, Q., and Zhang, H. Small, 2012, DOI: 10.1002/smll.201101016.

3. Thomas, J.M. and Thomas, W.J., Principles and Practice of Heterogeneous Catalysis, VCH, New York, (1997).

4. Gates, B.C., Catalytic Chemistry, Wiley \& Sons: New York,(1992).

5. Topsoe, H., Clausen, B.S. and Massoth, F.E., Hydrotreating Catalysis Springer-Verlag Berlin Heidelberg, New York (1996).

6. Bej, S.K, Maity, S.K. and Turaga, U.T., Energy \& Fuels, 18(5), 1227-1237, (2004).

7. Hamdy Farag, Abdel-Nasser A. El-Hendawy, Kinya Sakanishi, Masahiro Kishida and Isao Mochida; catalytic activity of synthesized nanosized molybdenum disulfide for the hydrodesulfurization of dibenzothiophene: Effect of $\mathrm{H}_{2} \mathrm{~S}$ partial pressure. Applied Catalysis B: Environmental; 91(1-2), 189-197, 7 September (2009).

8. Abdel-Nasser A. El-Hendawy, Robert J. Andrews, Andrew J. Alexander; Impact of Mo and $\mathrm{Ce}$ on growth of single-walled carbon nanotubes by chemical vapour deposition using MgO-supported Fe catalyst. Applied Surface Science, 255 7446-7450(2009). 
9. Wilson, K. and Miller, A.K., Am. Fuel Petrol. Manuf., AFPM Annual Meeting, pp. 193-205( 2013).

10. Farag, H. and Sakanishi, K., J.Catal. 225, 531-535(2004)

11. Chianelli, R.R. and Berhault, G., Catal. Today, 53, 357(1999).

12. Lacroix, M., geantet, C.G., Afanasiev, P. and Bezverkhyy, I., J.Catal., 204, 495(2001).

13. Feldman, Y., Wasserman, E., Srolovitz, D.J. and Tenne, R., Science, 267, (1995).

14. Hensen, E.J.M., Kooyman, P.J., van der Meer, Y., van de Kraan, A.M., de Beer, V.H.J., van Veen, J.A.R. and van Santen, R.A., J.Catal., 199, 224(2001).

15. Millan, M.M., Hyeon, T. and Suslick, K.S., J. Am. Chem. Soc. 120, 6189(1998).

16. Kuriki, Y., Uchida, K., Sekreta, E., Ohshima, S., Yumura, M., Ikazaki, F., Fuel Process. Technol. 59 189(1999).

17. Kouzu, M., Uchida, K., Kuriki, Y., Ikazaki, F., Appl. Catal. A 276, 241(2004).

18. Polyakov, M., Indris, S., Schwamborn, S., Mazheika, A., Poisot, M., Kienle, L., Bensch, W., Muhler, M., Gruner, W., J. Catal., 260 236(2008).

19. Farag, H., Energy \& Fuels, 16, 944-950 (2002).

20. JCPDS (Joint Committee for Powder diffraction Studies), International center for Diffraction Data, Swarthmore, PA, USA, (1986).

21. Klug, H.P. and Alexander, L.E., X-ray Diffraction Procedures for Polycrystalline and Amorphous Materials. John Wiley \& Sons: New York (1962).

22. Gregg, S.J. and Sing, K.S.W., Adsorption, Surface Area and Porosity, Academic press (1982).

23. Brunauer, S., Emmett, P.H. and Teller, E., J. Am.Chem. Soc. 60 (1938).

24. Lippens, B. C. and deBoer, J. H., Studies on pore systems in catalysts. J. Catal. 4, 319-323(1965).

25. Lippens, B. C., Linsen, B. G. and de Boer, J. H., J. Catalysis, 3, 32(1964).

26. Sellez-Perez, M. J. and Martin-Martinez, J. M., Application on $\alpha$ and $\mathrm{n}$ plots to N2 adsorption isotherms of activated carbons. J. Chem. Soc, Faraday Trans. 87 1237-1243(1991).

27. Selles-Perez M.J. and Martin-Martinez,J.M., Fuel ,70, 877(1991).

28. Abdel-Nasser A. El-Hendawy ,Influence of $\mathrm{HNO}_{3}$ oxidation on the structure and adsorptive properties of corncob-based activated carbon. Carbon,41,713-722 (2003) .

29. Wafaa E. Rashawan and Badie S. Girgis, Adsorption capacities of activated carbons derived from rice straw and water hyacinth in the removal of organic pollutants from water. Adsorp. Sci. Technol. 22, 3, 181-194 (2004).

30. Abdel-Nasser . El-Hendawy, Andrew J. Alexander, Robert J. Andrews, Gavin Forrest, Effects of activation schemes on porous, surface and thermal properties of activated carbons prepared from cotton stalks. J. Anal. Appl. Pyrolysis, 82, 272-278(2008) 
تأثير الطدن الميكانيكى على الخواص السطحية والثكل البلورى للجسيمات متناهية

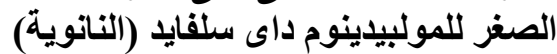

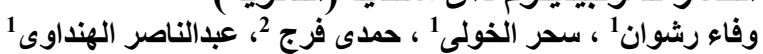

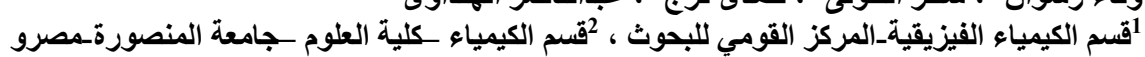
2لية الهندسة-جامعة كايوشا -اليابان.

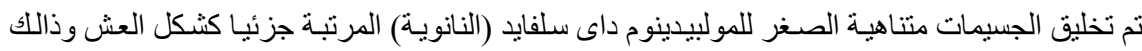

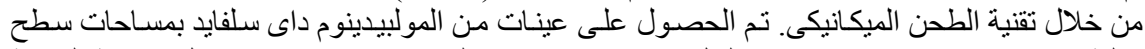

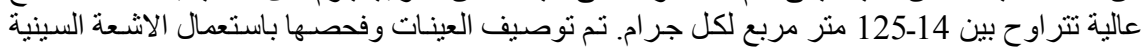

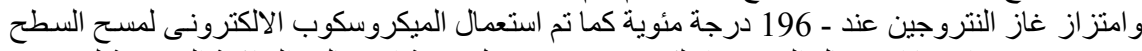

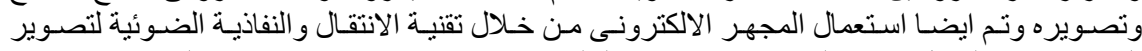

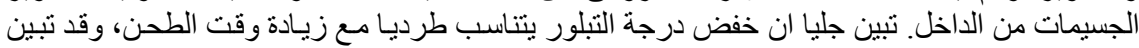

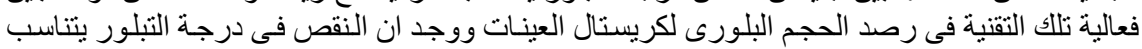
طرديا مع زمن الطحن ـ تبين ايضـا ان فعالية تقنية الطحن كطريقة طبيعية لقياس درجة التبلور و عدد لئل الطبقات

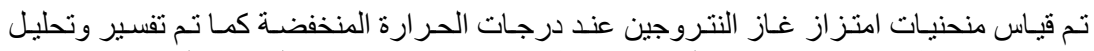

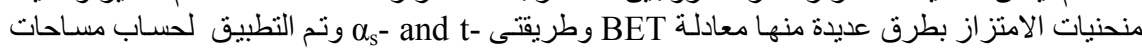

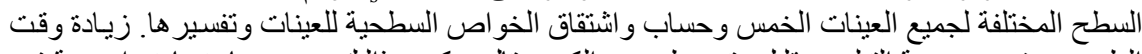

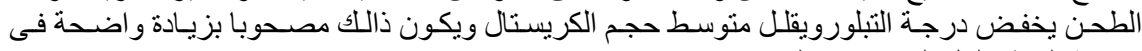
مساحة السطح لكل العينات قيد البحث. 